to knowledge of this fish and its parasites.

It seems that even the commensal relationship with jelly fishes is not without parasitic hazards for the young whiting. Of the forty-one young fish (15-42 $\mathrm{mm}$ in length), thirty were hosts to the copepodids of Caligus, which it is believed is itself attracted to the shadow of the medusal umbrella. After about 3 months, however, the association with the medusae ceases and the infestation with Caligus declines markedly.

Shotter's main intention was to demonstrate any differences between parasites of populations in different areas and where possible to relate them to feeding habits, physical characteristics of the differing environments and migrations. The comparisons possible between the parasites found in inshore and offshore whiting populations are striking. To cite but two of the ten species of internal parasite listed, the monogean Diclidophora merlangi was found in $62 \%$ of the offshore fish but in only half this number of the inshore population, and the digenean Podocotyle atomon occurred in only $0.8 \%$ of the former, but in $47 \%$ of the inshore fishes. Another digenean, Cryptocotyle lingua, occurred as metacercariae in $28 \%$ of the offshore fish but in $67 \%$ of those found in inshore waters.

Shotter relates quite convincingly the incidence of these parasites to the local environment of the fish and its food. Thus Diclidophora is a direct parasite without intermediate hosts. From the age of about 6 months, the whiting adopts a benthic mode of life and becomes susceptible to infestation from the bottom-living early stages of the monogean. Large infested whiting are found offshore so the continuance of the life cycle is ensured. Podocotyle, on the other hand, has as its first host certain mysiid and amphipod crustaceans which are an important food only for the inshore fish, and this parasite is characteristic of fishes which have spent a long time in inshore waters. Similarly Cryptocotyle has a life cycle involving the shore-dwelling gastropod Littorina littorea, a fish, and as final host one of several species of sea gull; it too is typical of inshore fishes.

The conclusion that Shotter draws from his study of the whiting's parasites is that any migration from the postulated inshore nursery areas to deeper water is probably restricted to a few individual fishes. He suggests that the majority of the inshore fishes may die prematurely as a result of their heavy burden of parasites and increased predation, and that two years is probably the maximal life span of an inshore whiting. It seems from his work that offshore stocks are not recruited from inshore nursery areas as had been thought, a result of some significance in a species which is heavily exploited by the fishing industry.

\section{OIL POLLUTION}

\section{Recovery of Salt Marsh}

from our Plant Ecology Correspondent

IN spite of the abundance of dogmatic assertions regarding the effects of pollution on the environment, which emanate from polluter and conservationist alike, there are surprisingly few experimental or observational data on changes in natural communities which can be directly related to pollution. This applies particularly to plant communities. Where experiments have been conducted, or observations made, they have usually been concerned with the effects of acute, high intensity pollution rather than with those of long-term, lowlevel chronic pollution.

The Field Studies Council Oil Pollution Research Unit, based at Orielton, Pembrokeshire, has been concerned with the long-term effects of successive oil spillages on maritime communities. It is known that shore communities recover well from single spillages, as is evidenced by the case history of the Torrey Canyon. At Milford Haven, where there is a large oil port, small, successive spillages of oil present a recurrent problem and their long-term effects are unknown.

In a recent report (Environ. Pollut., 4, 223 ; 1973), Baker describes the results of four years' observation on experimentally polluted areas of salt marsh in the Milford Haven area. In 1968 three areas of salt marsh which represented successional stages in salt marsh development were selected - low level Spartina marsh, mid level Puccinellia marsh and high level Juncus maritimus marsh. A block of randomized $2 \mathrm{~m} \times$ $5 \mathrm{~m}$ plots was set up in each of the three areas, one being a control, untreated plot and the others receiving monthly sprayings with Kuwait crude oil. Treatments consisted of two, four, eight, or twelve successive monthly sprayings. Changes in vegetation were recorded by means of point quadrats or, in the case of Spartina, tiller densities.

The effects of these treatments varied in the different communities. Four or more oilings produced significant reductions in Spartina density in the following year. All treatments had recovered within four years, but this was largely because of reinvasion of the plots from surrounding healthy colonies. Successive spillage on a wide scale would probably have a longer-lasting effect: eight or more sprayings in the mid-level salt marsh resulted in a spectacular reduction in the grass Puccinellia, which has shown no sign of subsequent recovery. Similar effects were observed in the highlevel marsh for Festuca rubra and the sea rush, Juncus maritimus. In the upper marsh the grass Agrostis stolonifera has taken advantage of the niches left vacant by the elimination of these species and has increased considerably.

These data will be of considerable value in predicting the effects of oil spillage on salt marshes. The smaller diversity of vegetation which results from such treatment could lead to lost stability, erosion and the redistribution of large quantities of mud. It would be interesting to know, however, whether the profound effects of eight or more sprayings would have resulted if the treatments had been more widely spread over the four-year period, rather than being concentrated into the first year. It may be that a critical recovery period of more than one month is required for the maintenance of vegetational stability.

\title{
DNA Conformation and Initiation of Transcription
}

WHEN the transcription of DNA by RNA polymerase is initiated the enzyme must bind specifically to the DNA template. Obviously therefore there are two ways in which this initiation step may be regulated, either by changing the structure of the polymerase or by changing the structure of the DNA template. The role of factors such as sigma factor which associate with the polymerase and affect the specificity of initiation has been partially elucidated, but less attention has been given to the effects of changes in conformation of the template DNA on initiation. Travers, Baillie and Pedersen have, however, been investigating this question by measuring the rate of synthesis in vitro of Escherichia coli ribosomal RNA by $E$. coli RNA poly. merase in various conditions which alter the configuration of the DNA template.

As they report in Nature New Biology next Wednesday (June 6), using a standard reaction mixture they noticed a lag in the rate of ribosomal RNA synthesis. By varying the order of addition of the components they quickly showed that the DNA template had to be "activated" before efficient transcription began; moreover this activation step seemed reversible. By varying the salt concentration in the incubation mixture, as well as the temperature of incubation and using T4 DNA as a template in some experiments, Travers and his colleagues reached the conclusion that "the substantial changes in both total and rRNA syntheses over a narrow temperature range bear a striking resem. blance to a nucleic acid melting curve and suggest that cooperative structural changes in the DNA template may occur". If these changes occur at promoter regions they would, of course, influence the pattern of transcription. In short the activity of a promoter may be controlled directly by controlling its conformation. 